\title{
Isolated, neglected, traumatic scapular spine fractures: Report of five cases
}

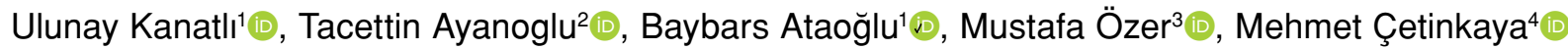

\begin{abstract}
'Department of Orthopedics and Traumatology, Gazi University Faculty of Medicine, Ankara, Turkey ${ }^{2}$ Department of Orthopedics and Traumatology, Bolu Abant Izzet Baysal University, Bolu, Turkey ${ }^{3}$ Department of Orthopedics and Traumatology, Necmettin Erbakan University, Faculty of Medicine, Konya, Turkey ${ }^{4}$ Department of Orthopedics and Traumatology, Cam Sakura City Hospital, Istanbul, Turkey ${ }^{5}$ Department of Orthopedics and Traumatology, TOBB University of Economics and Technology, Ankara, Turkey
\end{abstract}

As rare injuries, scapular fractures constitutes $1 \%$ of all fractures, and only $1 \%$ of those involve the scapular spine. ${ }^{[1]}$ Although most of these fractures occur as a result of high-energy trauma, isolated scapular spine fractures can also be seen after reverse shoulder arthroplasty or in the form of stress fracture. ${ }^{[2]}$

Scapular spine fractures mostly present as a late-diagnosis or a neglected disorder, as of the scapular overlapping with the thoracal bones on the roentgenogram and injuries to the thoracic cage and soft tissues around the shoulder girdle. These fractures are also confused with other shoulder problems such as rotator cuff pathologies and have a high tendency of a delayed diagnosis and nonunion. ${ }^{[1]}$

Received: October 18, 2021

Accepted: December 20, 2021

Published online: December 22, 2021

Correspondence: Tacettin Ayanoglu, MD. Bolu Abant İzet Baysal Üniversitesi Tıp Fakültesi Ortopedi ve Travmatoloji

Anabilim Dalı, 14030 Bolu, Türkiye.

E-mail: drtacettin@gmail.com

Doi: $10.52312 /$ jdrscr.2022.7

Citation: Kanatı U, Ayanoglu T, Ataoglu B, Özer M, Çetinkaya M, Aktas E. Isolated, neglected, traumatic scapular spine fractures: Report of five cases. Jt Dis Relat Surg Case Rep 2022;1(1):27-30.

C2022 All right reserved by the Turkish Joint Diseases Foundation

This is an open access article under the terms of the Creative Commons Attribution-NonCommercial License, which permits use, distribution and reproduction in any medium, provided the original work is properly cited and is not used for commercial purposes (http://creativecommons.org/licenses/by-nc/4.0/).

https://www.casereportsjointdrs.org

\section{ABSTRACT}

Scapular spine fractures commonly present as a late-diagnosis or a neglected disorder due to their indistinct appearance and overlapping on radiographs. We report patients diagnosed with scapular spine fracture nonunion or pseudoarthrosis. All patients had chronic posterior shoulder pain and tenderness on the spine of the scapula with palpation, as well as a palpable crepitation. One of the pseudoarthrosis patients had major movement in the fracture line. Local anesthetic injection was used to determine the diagnosis in other patients. Radiological images confirmed the diagnoses. Patients were operated with reduction and rigid fixation by $2.4 / 2.7 \mathrm{~mm}$ locking plate. Misdiagnosed scapular spine fractures can be the cause of a chronic painful shoulder and without clinical suspicion they may go undiagnosed for many years, as demonstrated in this case series. In conclusion, we recommend considering nonunion and pseudoarthrosis during physical and radiological evaluation of patients with posterior shoulder pain.

Keywords: Neglected fractures, open reduction and internal fixation, pseudoarthrosis, scapular spine fractures.

There are few case reports of isolated traumatic spinal fractures in the literature. Herein, we present the largest case series of pseudoarthrosis of neglected scapular spine fractures to the best of our knowledge.

\section{CASE REPORT}

Five patients, two males and three females, with a mean age of $45.8 \pm 10.0$ years, diagnosed with neglected scapular spine fracture between January 2011 and February 2016 were evaluated retrospectively (Table I). All patients had a history of trauma with nonunion or pseudoarthrosis of the scapular spine. All patients 
TABLE I

Demographic characteristics of patients

\begin{tabular}{|c|c|c|c|c|c|}
\hline Patients & 1 & 2 & 3 & 4 & 5 \\
\hline Age (year) & 57 & 56 & 36 & 38 & 42 \\
\hline Sex & Male & Male & Female & Female & Female \\
\hline Side & Right & Right & Right & Left & Left \\
\hline History & $\begin{array}{l}\text { Motor vehicle } \\
\text { accident }\end{array}$ & Direct trauma & $\begin{array}{c}\text { Motor vehicle } \\
\text { accident }\end{array}$ & Direct trauma & $\begin{array}{l}\text { Motor vehicle } \\
\text { accident }\end{array}$ \\
\hline Time of diagnosis & 3 months & 1 year & 5 months & 1 year & 3 months \\
\hline Healing & Non-union & Pseudo-arthrosis & Non-union & Pseudo-arthrosis & Non-union \\
\hline Treatment & Single plate & Double plate & Single plate & Single plate & Double plate \\
\hline Clinical outcome & Pain free & Pain free & Pain free & Pain free & $\begin{array}{c}\text { Pain over scapular } \\
\text { spine }\end{array}$ \\
\hline Radiological outcome & Healed & Healed & Healed & Healed & Healed \\
\hline Complications & - & - & - & - & Plate irritation \\
\hline Last follow-up & 35 months & 24 months & 20 months & 18 months & 15 months \\
\hline
\end{tabular}

were informed that data from the case would be submitted for publication and gave their consent.

The patients were previously evaluated in external institutes and were consulted to our clinic after between three to five months and two after 12 months. Three fractures were a result of motor vehicle accidents and two occurred with direct trauma. All patients had posterior shoulder pain that did not alleviate following initial trauma. Physical examination revealed posterior shoulder pain and all patients experienced tenderness on the spine of the scapula with palpation and apparent crepitation
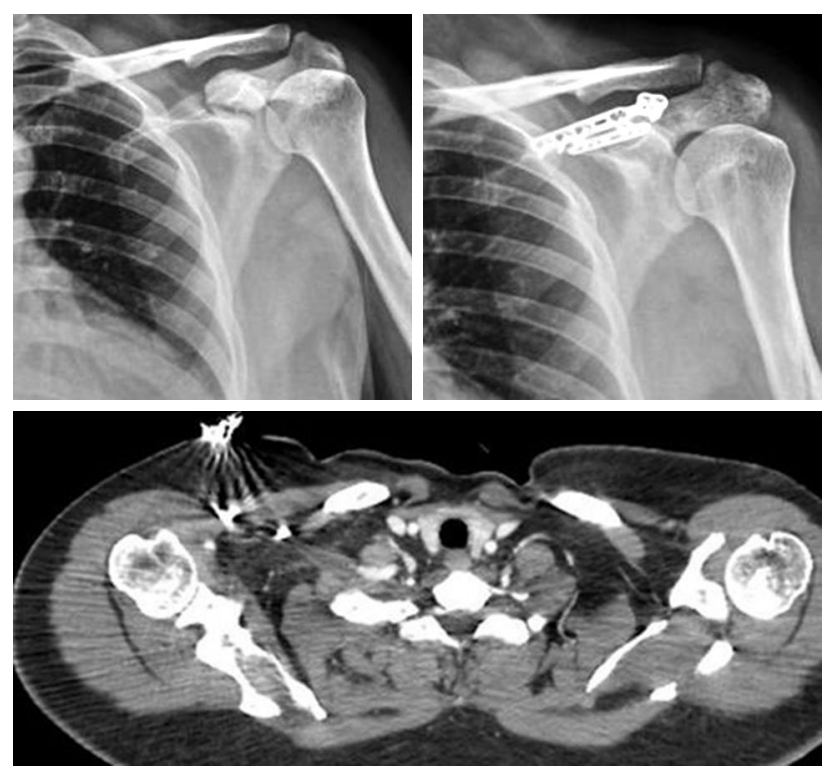

Figure 1. Pre- and postoperative radiographs and computed tomography images of nonunion of the scapular spine in left shoulder of a 42-year-old female patient. over the scapular spine. Although patients were comfortable during internal and external rotation, active-passive abduction and forward flexion was found to be painful at $90^{\circ}$. Local anesthesia was applied to the area of pain and it was tested whether the pain decreased or not. Radiographs and computed tomography (CT) images revealed fracture of the scapular spine (Figures 1 and 2). All patients underwent surgical intervention. One patient additionally had a full-thickness rotator cuff tear with scapular spine fracture. Following fracture treatment, arthroscopic rotator cuff repair was performed at six months.

\section{Surgical technique}

Surgery was performed in the lateral decubitus position. A $10-\mathrm{cm}$ long skin incision was made parallel to the spine of the scapula. Subcutaneous soft tissues were dissected and the plane between
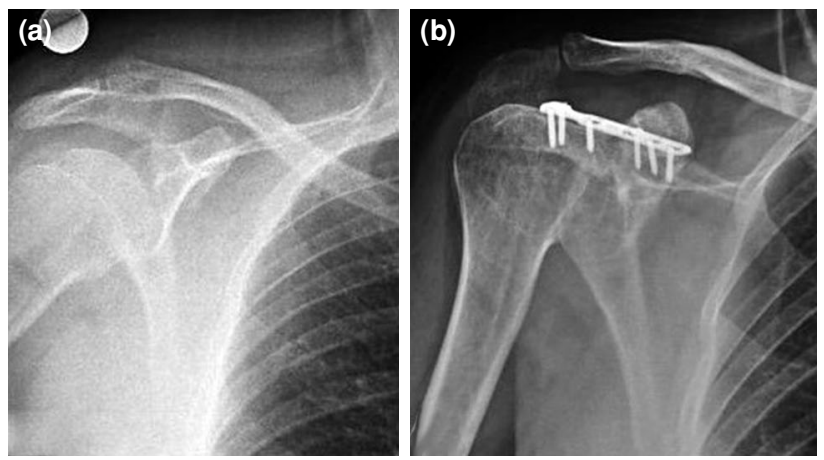

Figure 2. (a) A preoperative radiograph showing nonunion of the scapular spine in left shoulder and (b) an intraoperative radiograph showing fracture fixation with a plate-screw system in a 57-year-old male patient. 


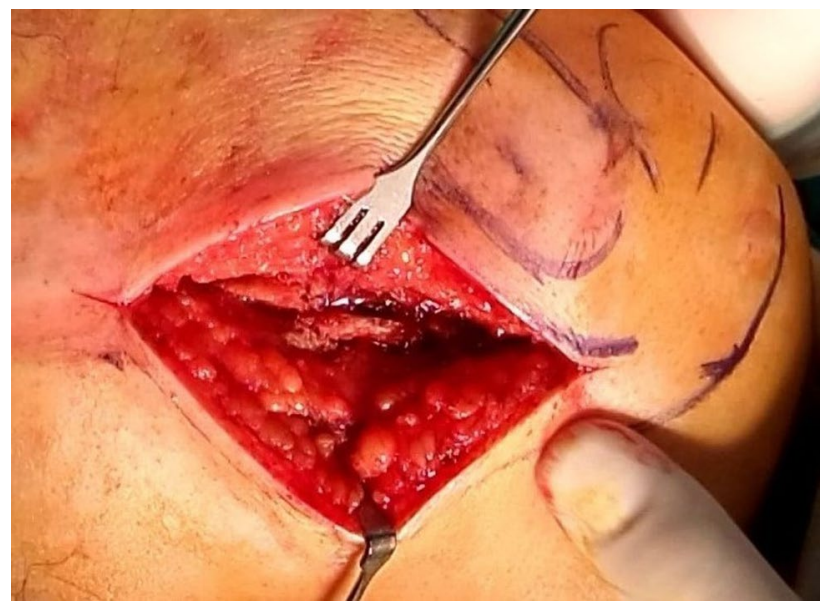

Figure 3. An intraoperative image of the fracture line.

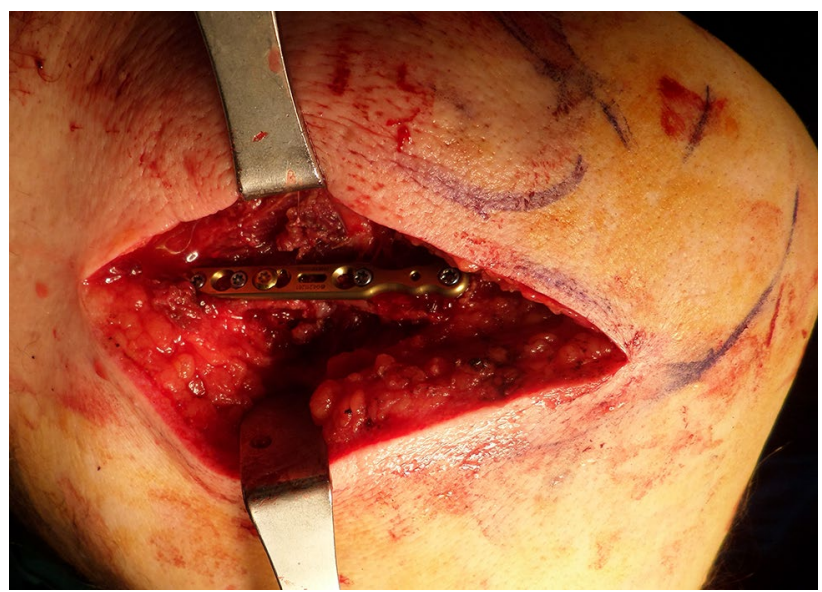

Figure 4. An intraoperative image of the fracture after fixation.

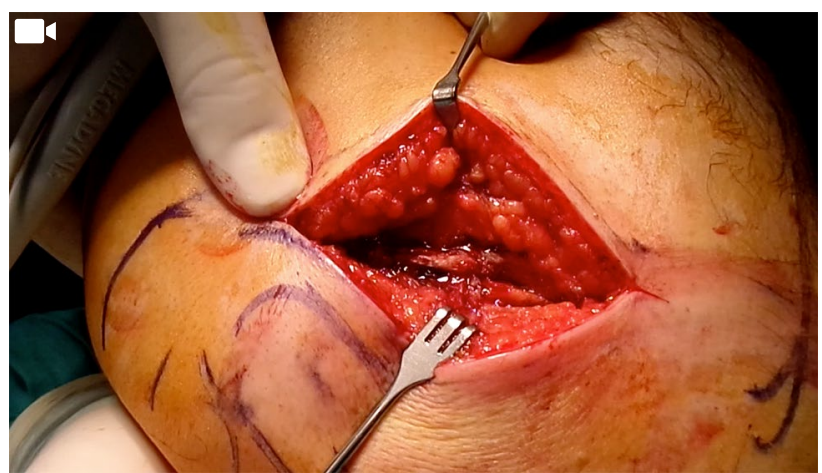

Video 1. Click image to view online. Intraoperative video of the fracture line.

deltoid-trapezius was used to expose scapular spine (Figure 3) (Video 1). Fibrous tissue was removed with a curette. Following reduction, rigid fixation was achieved using a 2.4/2.7 mm locking plate (Figure 4). Double-plate fixation was deemed necessary to achieve stability in two cases. The detached muscles were re-attached. The shoulder was immobilized in a Velpeau bandage for six weeks. Passive exercises were initiated immediately on postoperative day 1 and active-assisted exercises were initiated at the beginning of the third week. Active range of motion exercises were encouraged beginning at the postoperative six weeks and onwards.

Fracture healing was evaluated clinically and on radiographs in follow-up visits every three months. By the end of six months, all fractures healed clinically and radiographically.

All patients were pain-free at their last follow-up visits, except for one patient who had local tenderness at the operation site due to plate irritation (Table I).

\section{DISCUSSION}

Scapular fractures are rare injuries, comprising $1 \%$ of all fractures and $5 \%$ of shoulder girdle fractures. Scapular spine fractures are rarer, consisting only $6 \%$ of scapular fractures. The reasons for the rarity of this fracture are the width of the recoil movement and thick edges between muscles. Although fractures of the scapula usually occur as a result of high-energy trauma, stress riser may also play an important role in the etiology of non-traumatic scapular spine fractures during sport activities, work-related activities of the upper extremity, coughing, and prolonged oral corticosteroid treatment. ${ }^{[3]}$ Interestingly, scapular spine fractures may occur after reverse shoulder arthroplasty, as a consequence of altered biomechanics. ${ }^{[2]}$ Rotator cuff-tear arthropathy can act as a stress riser and superior migration of the humeral head results in microtrauma of the acromion which, in time, can lead to a fracture, usually at the base of the acromion. ${ }^{[4]}$ In our series, all patients had a history of high-energy trauma.

Scapular spine fractures are frequently misdiagnosed, ${ }^{[1]}$ leading to treatment delay. One of the main reasons is overlapping of the scapula with the thoracal bones on anteroposterior radiographs. Injuries to the thoracic cage and soft tissues around the shoulder girdle may also mask a scapular spine fracture. In our series, all five cases were undiagnosed and had delayed admissions to our institute. Considering the time points, development of pseudoarthrosis and nonunion was the consequence. Pseudoarthrosis of the spine of the scapula can predispose rotator cuff arthropathy and subacromial impingement. The deltoid muscle may pull the fracture fragments inferiorly and cause weakened rotator cuff 
function and loss of active arm elevation, which is named pseudorupture of the rotator cuff. ${ }^{[5]}$ Sagging of the lateral spine and acromion effectively produces narrowing of the supraspinatus outlet. ${ }^{[6]}$ Scapular spine fracture represents a partial failure of the lateral scapular suspension system and this mechanism can also cause subacromial impingement syndrome. ${ }^{[7]}$ If the physical examination is not performed adequately, a scapular spine fracture can be masked with rotator cuff tears. Cases were reported in which rotator cuff tear was repaired without fracture treatment. ${ }^{[8]}$ One of our patients had a one-year history of scapular spine fracture and was accompanied by a rotator cuff tear. A thorough history revealed that she had impingement symptoms prior to the trauma. Fixation of the fracture was performed initially followed by an arthroscopic rotator cuff repair, six months after confirming the fracture healing clinically and radiographically. Obtaining a detailed medical history (i.e., trauma, sports activities, corticosteroid use), as well as performing an in-depth examination of the shoulder girdle and palpation of the scapular spine is of great importance in patients with persistent shoulder pain. Tenderness and apparent crepitation should arise suspicion for scapular spine fracture as seen in all our patients.

Although most acute scapular spine fractures have a tendency to heal with conservative treatment yielding good functional results, delayed management is often problematic. ${ }^{[1]}$ Three months can be considered as a cut-off for conservative treatment success or classification as a delayed diagnosis. Surgical treatment methods should be advocated in symptomatic patients presenting three months after the fracture. ${ }^{[5]}$ All of our patients had a delayed diagnosis and were symptomatic during daily activities. Radiographs and CT images revealed nonunions or pseudoarthroses of the scapular spine and, thus, surgical intervention was planned for all cases.

Lateral spine fractures near the acromion can be surgically treated with a Kirschner wire and tension band technique. ${ }^{[9]}$ For more proximal and medially displaced fractures involving the spine of scapula, plate fixation is advocated. ${ }^{[10]}$ Compression of the pseudoarthrosis site with one cancellous lag screw, without debriding or grafting has also been described. ${ }^{[1]}$ We preferred to use plate-screw fixation in all our patients following debridement of the pseudoarthrosis site. All fractures healed at six months of follow-up. Four patients were pain-free with range of motion within normal limits; however, one patient with double-plate fixation had pain over the scapular spine at the end of 15 months due to plate irritation.

In conclusion, isolated scapular spine fractures are rare and commonly misdiagnosed fractures due to inadequate physical or radiological examination. Palpation of the scapular spine for any tenderness or apparent crepitation is critical for suspecting the fracture, followed by a comprehensive evaluation of radiological work-up. A delayed diagnosis and pseudoarthrosis necessitating surgical intervention are likely to occur in absence of clinical suspicion. Fixation of the fracture with a plate-screw system can be the preferred surgical modality with good functional outcomes.

\section{Declaration of conflicting interests}

The authors declared no conflicts of interest with respect to the authorship and/or publication of this article.

\section{Funding}

The authors received no financial support for the research and/or authorship of this article.

\section{REFERENCES}

1. As-Sultany M, Tambe A, Clark DI. Nonunion of a scapular spine fracture: Case report and management with open reduction, internal fixation, and bone graft. Int J Shoulder Surg 2008;2:64-7.

2. Nicolay S, De Beuckeleer L, Stoffelen D, Vanhoenacker F, Pouillon M. Atraumatic bilateral scapular spine fracture several months after bilateral reverse total shoulder arthroplasty. Skeletal Radiol 2014;43:699-702.

3. Franco M, Albano L, Blaimont A, Barrillon D, Bracco J. Spontaneous fracture of the lower angle of scapula. Possible role of cough. Joint Bone Spine 2004;71:580-2.

4. Yamaguchi K, Sher JS, Andersen WK, Garretson R, Uribe JW, Hechtman K, et al. Glenohumeral motion in patients with rotator cuff tears: A comparison of asymptomatic and symptomatic shoulders. J Shoulder Elbow Surg 2000;9:6-11.

5. Hardegger FH, Simpson LA, Weber BG. The operative treatment of scapular fractures. J Bone Joint Surg [Br] 1984;66:725-31.

6. Wright RW, Heller MA, Quick DC, Buss DD. Arthroscopic decompression for impingement syndrome secondary to an unstable os acromiale. Arthroscopy 2000;16:595-9.

7. Lambert S, Kellam JF, Jaeger M, Madsen JE, Babst R, Andermahr J, et al. Focussed classification of scapula fractures: Failure of the lateral scapula suspension system. Injury 2013;44:1507-13.

8. Copuroglu C, Tan L, Copuroglu E, Ciftdemir M, Ozcan M. Pseudo-arthrosis of the spine of the scapula: A case report with a delayed diagnosis. Strategies Trauma Limb Reconstr 2014;9:173-7.

9. Ogawa K, Naniwa T. Fractures of the acromion and the lateral scapular spine. J Shoulder Elbow Surg 1997;6:544-8.

10. Robinson CM, Court-Brown CM. Non-union of scapula spine fracture treated by bone graft and plate fixation. Injury 1993;24:428-9. 